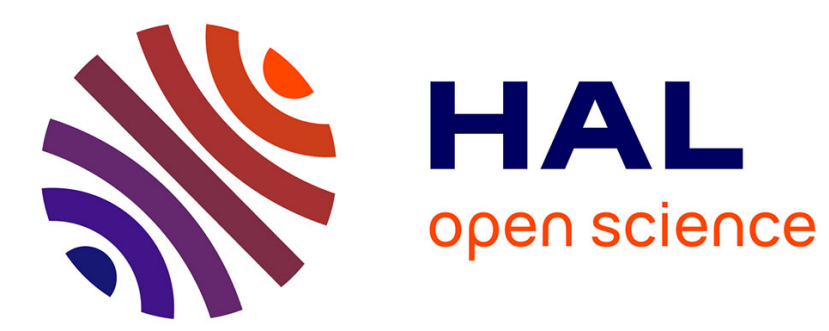

\title{
Oxidative cross-linking of chemically and enzymatically modified sugar-beet pectin
}

\author{
Fabienne F. Guillon, J.F. Thibault
}

\section{To cite this version:}

Fabienne F. Guillon, J.F. Thibault. Oxidative cross-linking of chemically and enzymatically modified sugar-beet pectin. Carbohydrate Polymers, 1990, 12 (4), pp.353-374. hal-02703902

\section{HAL Id: hal-02703902 \\ https://hal.inrae.fr/hal-02703902}

Submitted on 1 Jun 2020

HAL is a multi-disciplinary open access archive for the deposit and dissemination of scientific research documents, whether they are published or not. The documents may come from teaching and research institutions in France or abroad, or from public or private research centers.
L'archive ouverte pluridisciplinaire HAL, est destinée au dépôt et à la diffusion de documents scientifiques de niveau recherche, publiés ou non, émanant des établissements d'enseignement et de recherche français ou étrangers, des laboratoires publics ou privés. 


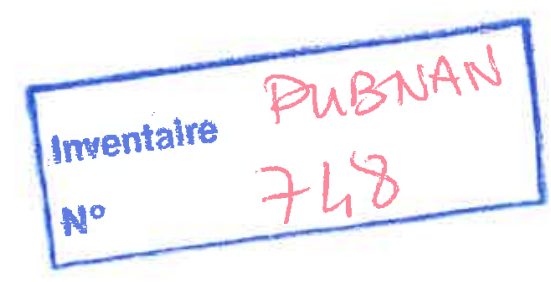

\title{
Oxidative Cross-Linking of Chemically and Enzymatically Modified Sugar-Beet Pectin
}

\author{
Fabienne Guillon* \& Jean-François Thibault \\ Institut National de la Recherche Agronomique, Laboratoire de Biochimie et \\ Technologie des Glucides, BP 527, 44026 Nantes, France
}

(Received 6 February 1989; accepted 10 April 1989)

\begin{abstract}
Hot acid-soluble pectins from sugar-beet pulp which do not gel in the presence of persulfate were submitted to hydrolysis with acid under different conditions of concentration, temperature and time, or with different combinations of enzymes. All the modified pectins have been chemically characterised and tested for their gelling capacity with persulfate ions. They varied primarily in the structure of the side-chains and only those obtained from cold acid hydrolysis and from degradation by arabinofuranosidase were able to gel. Accessibility of the feruloyl groups carried by the arabinose side-chains appeared essential for the gelling of beet pectins with persulfate.
\end{abstract}

\section{INTRODUCTION}

There is a potential interest in the use of sugar-beet pulp as a source of pectin because it contains high amounts of pectin (15-30\%) (McCready, 1966; Beldman et al., 1982; Bertin et al., 1988; Michel et al., 1988; Phatak et al., 1988) and it is available in large quantities at a low cost. Attempts to use sugar-beet pectins as substitute for citrus or apple pectins have failed because they have poor gelling qualities which have been ascribed to their high content of acetyl groups and to their low molecular weight (Pippen et al., 1950). However, the fine structure of the sugar-beet pectins has been studied (Rombouts \& Thibault, 1986a, $b$; Guillon \& Thibault, 1988, 1989; Guillon et al., 1989) and partly as a result, a new way of producing sugar-beet pectin gels has been deve-

*Present address: Institut National de la Recherche Agronomique, Laboratoire de Technologie Appliquée à la Nutrition, BP 527, 44026 Nantes Cédex 03, France. 
loped, (Rombouts et al., 1983; Thibault \& Rombouts, 1986). They are made up of homogalacturonic regions ('smooth regions') which carry most of the acetyl groups $(\sim 75 \%)$ (Rombouts \& Thibault, 1986a) and of rhamnogalacturonic regions carrying essentially highly branched $(1 \rightarrow 5)$ linked arabinans and fairly linear $(1 \rightarrow 4)$-linked galactans with a low degree of polymerisation (Guillon \& Thibault, 1989; Guillon et al., 1989). A distinctive feature of commercial pectins, in addition to the presence of acetyl groups, is that they contain feruloyl groups esterlinked to the neutral sugar side-chains. A proportion $(30 \%)$ is linked to the arabinans and the remainder to the galactans (Guillon \& Thibault, 1989; Guillon et al., 1989) as previously observed for pectins from spinach cell walls (Fry, 1982, 1983). These substituents can be involved in cross-linking reactions with hydrogen peroxide/peroxidase (Rombouts et al., 1983) or ammonium persulfate (Thibault \& Rombouts, 1986) leading to gel formation. These gels show interesting properties such as a high water holding capacity (Thibault, 1986). The study of the gelation of pectins extracted from the pulp or from cossettes under different conditions led to the conclusion that not all the pectins are able to form gels and that no simple relationship exists between the gelling capacity and the chemical composition of the pectins (Thibault, 1988).

In the present paper, the fine structure of the neutral sugar side-chains of one pectin which is not able to form gels, has been varied by acid and by enzymes in order to correlate gelation to structural changes in the pectin.

\section{EXPERIMENTAL}

\section{Material}

\section{Sugar-beet pulp}

Sugar-beet pulp from the 'Genérale Sucrière factory in Artenay (France) was ground and particles between 250 and $500 \mu \mathrm{m}$ were extracted by potassium oxalate for $30 \mathrm{~min}$ at room temperature as described by Bertin et al. (1988). The residue was extensively washed with water and accounted for $88.6 \%$ of the initial material.

\section{Sugar-beet pectins}

The undried residue from potassium oxalate extraction $(82 \mathrm{~g})$ was heated with $0.05 \mathrm{M} \mathrm{HCl}$ ( 1.4 liters) for $30 \mathrm{~min}$ at $85^{\circ} \mathrm{C}$ and cooled. The suspen- 
sion was filtered through $\mathrm{G} 4$ sintered glass and the filtrate neutralised to $\mathrm{pH} 4.5$ with $2 \mathrm{M} \mathrm{NaOH}$. The extraction was carried out three times. The neutralised filtrates were pooled, ultrafiltered on a Millipore Pellicon Cassettes System (PTGC 0.0005 cassettes), against running water at 15 liters $\mathrm{h}^{-1}$, in order to reduce the volume by $75 \%$. The retentate was treated with four volumes of aqueous $95 \%$ ethanol and kept overnight at $4^{\circ} \mathrm{C}$. The precipitate was collected on a G3 sintered glass filter, washed with aqueous $70 \%$ ethanol, dried by solvent exchange and then air dried. The pectins were purified by precipitation with cupric ions as described by Michel et al. (1985).

\section{Enzymes}

The enzymes $\alpha$-L-arabinofuranosidase B (Araf-ase, E.C.3.2.1.55), endo$(1 \rightarrow 5$ )- $\alpha$-L-arabinanase (endo-Ara-ase, E.C.3.2.1.99), $\beta$-D-galactosidase (Gal-ase, E.C.3.2.1.23), endo-( $\rightarrow 4)-\beta$-D-galactanase (endo-Gal-ase, E.C.3.2.1.89) were isolated from a pectinase preparation from Aspergillus niger (Voragen et al., 1987; Rombouts et al., 1988). Endopolygalacturonase (endo-PG-ase, E.C.3.2.1.15) was purified from a preparation of Aspergillus niger(Thibault \& Mercier, 1977).

\section{Analytical methods}

All the values were calculated on a moisture free basis. Galacturonic acid and neutral sugars (expressed as arabinose) were determined by the automated $m$-hydroxybiphenyl (Thibault, 1979) and orcinol (Tollier \& Robin, 1979) methods, respectively, the latter being corrected for interfering galacturonic acid. Individual neutral sugars were determined after hydrolysis with $1 \mathrm{M} \mathrm{H}_{2} \mathrm{SO}_{4}\left(100^{\circ} \mathrm{C}, 2 \mathrm{~h}\right)$ as their alditol acetates by GLC (Blakeney et al., 1983). Methanol and acetic acid were determined by HPLC (Aminex HPX 87H) (Voragen et al., 1986) and the degrees of methylation and acetylation were expressed as moles of ester per 100 mol of galacturonic acid residues. Total phenol and proteins were measured by colorimetry (Potty, 1969). Phenolic acids were liberated by the treatment of pectins with $2 \mathrm{M} \mathrm{NaOH}$ at $35^{\circ} \mathrm{C}$ for $2 \mathrm{~h}$ under argon. After acid treatment ( $\mathrm{pH} 2$ ) and extraction using diethyl ether, they were analysed by HPLC (Crépeau \& Thibault, 1988) on Rsil C18 $5 \mu \mathrm{m}$ with water/methanol/acetic acid $(73 / 26 / 1, \mathrm{v} / \mathrm{v})$ as eluent at a flow rate of 0.9 $\mathrm{ml} \mathrm{min}^{-1}$. Feruloyl groups were determined spectrophotometrically at $375 \mathrm{~nm}$ on freshly prepared solutions of pectin in $0.066 \mathrm{M}$ glycine/ $\mathrm{NaOH}$ ( $\mathrm{pH} \mathrm{10}$ ) buffer using a molar extinction coefficient of 31600 (Fry, 1982). Feruloyl groups in column eluates are monitored by spectrophotometry at $375 \mathrm{~nm}$, the $\mathrm{pH}$ of the fractions being adjusted to 10 by 1 
M NaOH. Reducing sugars were determined by the method of Nelson (1944).

\section{Enzymatic degradations of the neutral sugar side-chains}

Arabinanases and galactanases were used on sugar-beet pectins, separately, in sequence or in combination. The reaction medium contained sugar-beet pectins $(0 \cdot 4 \%, w / v)$, enzyme(s) (arabinanases in a final concentration of $20 \mu \mathrm{g} \mathrm{ml}^{-1}$ of proteins and galactanase in a final concentration of $1 \mu \mathrm{g} \mathrm{ml}^{-1}$ of proteins) in $0.05 \mathrm{M}$ sodium acetate buffer, at $\mathrm{pH} 5$ (Guillon et al., 1989). Incubation was carried out at $30^{\circ} \mathrm{C}$ for 24 or $48 \mathrm{~h}$; the reaction was monitored by the increase in the reducing group. The reaction was stopped by heating at $\sim 100^{\circ} \mathrm{C}$ for $5 \mathrm{~min}$. The digest was dialysed against distilled water or acetate buffer and the retentates freeze-dried or incubated with enzyme.

\section{Mild acid hydrolysis}

The pectins $(100 \mathrm{mg})$ were treated with $0.1 \mathrm{M}$ trifluoroacetic acid $(10 \mathrm{ml})$ at $25^{\circ} \mathrm{C}$ for $8 \mathrm{~h}, 24 \mathrm{~h}$ and $72 \mathrm{~h}$, or with $0.05 \mathrm{M}$ trifluoroacetic acid $(10 \mathrm{ml})$ at $100^{\circ} \mathrm{C}$ in a sealed tube for $1-12 \mathrm{~h}$. The acid was evaporated in vacuo and the residues were dissolved in $20 \mathrm{ml}$ of water. The hydrolysis products were extensively dialysed against distilled water. The dialysates were pooled, concentrated in a rotary evaporator and frozen. The retentates were freeze-dried.

\section{Isolation of the 'hairy' fragments}

The sugar-beet pectins were first demethylated and deacetylated in cold alkali (Rombouts \& Thibault, $1986 b$ ). The reaction mixture contained 2 $\mathrm{mg} \mathrm{ml}^{-1}$ pectins in $0.05 \mathrm{M}$ sodium acetate buffer $(\mathrm{pH} 4.2)$, at $30^{\circ} \mathrm{C}$ for $24 \mathrm{~h}$ and endo-PG-ase ( $\left.2 \mathrm{nkat} \mathrm{ml}^{-1}\right)$. The 'hairy' fragments were isolated from the endo-polygalacturonase digest by gel filtration chromatography as previously described (Guillon \& Thibault, 1988).

\section{Chromatography}

Ion-exchange chromatography was performed on a column $\left(6 \times 1.6 \mathrm{~cm}^{2}\right)$ of Deae-Sephacel equilibrated with 0.05 м sodium acetate buffer $(\mathrm{pH}$ 
4.8). Pectic substances ( $4 \mathrm{mg}$ ) were loaded onto the column and the gel was washed with $50 \mathrm{ml}$ of $0.05 \mathrm{M}$ sodium acetate buffer ( $\mathrm{pH} \mathrm{4.8).} \mathrm{The}$ bound material was eluted with a linear sodium acetate buffer gradient at pH 4.8 (ionic strength $0.05-0.8 \mathrm{M}, 90 \mathrm{ml}$ ). Fractions of $5 \mathrm{ml}$ were collected.

The pectins $(6 \mathrm{mg})$ were injected onto a Sepharose CL-2B column $\left(86 \times 2 \mathrm{~cm}^{2}\right)$ and eluted by a sodium acetate buffer (ionic strength $=0.1$ $\mathrm{M}, \mathrm{pH} \mathrm{4}$ ) at a flow rate of $20 \mathrm{ml} \mathrm{h}^{-1}$. Fractions of $4 \mathrm{ml}$ were collected and analysed for their content of galacturonic acid, neutral sugars and feruloyl groups. Results were expressed as a function of $\mathrm{K}_{\mathrm{av}}$.

Chromatography on Bio-Gel P-2 was performed as previously described (Guillon \& Thibault, 1989). About $2 \mathrm{mg}$ of material is injected onto the column $\left(203 \times 1.6 \mathrm{~cm}^{2}\right)$ eluted at $60^{\circ} \mathrm{C}$ in the descending direction with degassed $0.1 \mathrm{M}$ sodium acetate buffer $\left(\mathrm{pH} \mathrm{3.6)}\right.$ ) at $50 \mathrm{ml} \mathrm{h}^{-1}$. Aliquots of the eluate were continuously analysed for their contents of galacturonic acid and neutral sugars and $5 \mathrm{ml}$ fractions were collected. Results were expressed as a function of the elution volume.

\section{Viscosity measurements}

Intrinsic viscosity values $\left([\eta\rceil, \mathrm{ml} \mathrm{g}^{-1}\right)$ are obtained at $25^{\circ} \mathrm{C}$ with an automatic Fica viscometer. Solutions of pectins $\left(3 \mathrm{mg} \mathrm{ml}^{-1}\right)$ in $0.155 \mathrm{M}$ sodium chloride are used and diluted with $0.155 \mathrm{~m}$ sodium chloride. The viscosity-average molecular weights $\left(M_{\mathrm{v}}\right)$ are calculated according to Owens et al. (1946).

\section{Kinetics of action of ammonium persulfate}

The acid-form of the pectins was obtained by percolating salt-free solutions through a strong resin (Amberlite IR 120) and the capacity was determined by conductimetric titrations. The rate of disappearance of the feruloyl groups was followed by spectrophotometry. Periodically, aliquots were mixed with glycine- $\mathrm{NaOH}$ buffer ( $\mathrm{pH}$ 10; final molarity, $0.066 \mathrm{M}$ ) and the absorbance at $375 \mathrm{~nm}$ was recorded (Thibault et al., 1987).

\section{Gelation tests}

Solutions of pectins were made $(1.5 \%$ in $0.01 \mathrm{~m}$ ammonium persulfate) and left at $25^{\circ} \mathrm{C}$. Gelation was followed by visual observation. 


\section{RESULTS}

\section{Preparation of the pectic samples}

\section{Characterisation of the initial pectins}

Pectins were obtained by extraction with hot dilute acid from sugar-beet pulp previously extracted with potassium oxalate. They accounted for $17.2 \%(\mathrm{w} / \mathrm{w})$ of the initial material. The crude extract was characterised by a low content of galacturonic acid $(47.9 \%)$ and a relatively high content of neutral sugars $(24.2 \%)$. They were chromatographed on DEAESephacel. The galacturonic acid recovery was $94 \%$ and pectins eluted as a single peak at an ionic strength of $0 \cdot 48$, indicating that they are homogeneous in the degree of methylation. As some neutral sugars $(5.8 \%$ of the injected material) were not bound to the gel, pectins were purified by precipitation with cupric ions with a recovery of $64.9 \%$. The purified pectins were rechromatographied on the same gel and the only change was the amount of unbound material which decreased to $<1 \%$ of the

TABLE 1

Characteristics of the Purified Pectins Before and After Hydrolysis with $0.1 \mathrm{M}$ Trifluoroacetic Acid at $25^{\circ} \mathrm{C}$

\begin{tabular}{|c|c|c|c|c|c|}
\hline & \multicolumn{5}{|c|}{ Reaction time (h) } \\
\hline & 0 & 4 & 8 & 26 & 72 \\
\hline & \multicolumn{5}{|c|}{ Recovery (\%) } \\
\hline & & $\sim 100$ & $99 \cdot 7$ & $99 \cdot 5$ & $98 \cdot 7$ \\
\hline Galacturonic acid $^{a}$ & $58 \cdot 8$ & $58 \cdot 8$ & $59 \cdot 0$ & $59 \cdot 1$ & $59 \cdot 6$ \\
\hline Rhamnose & $3 \cdot 2$ & $3 \cdot 2$ & $3 \cdot 2$ & $3 \cdot 2$ & $3-2$ \\
\hline Arabinose & $13 \cdot 2$ & $13 \cdot 1$ & $12 \cdot 8$ & $12 \cdot 6$ & $12 \cdot 0$ \\
\hline Xylose & $0 \cdot 3$ & $0 \cdot 0$ & $0 \cdot 0$ & 0.0 & $0 \cdot 0$ \\
\hline Galactose & $7 \cdot 1$ & $7 \cdot 2$ & $7 \cdot 2$ & $7 \cdot 2$ & $7 \cdot 3$ \\
\hline Glucose & $0 \cdot 4$ & 0.4 & 0.4 & 0.4 & $0 \cdot 4$ \\
\hline Feruloyl groups ${ }^{b}$ & $0 \cdot 7$ & $0 \cdot 7$ & 0.6 & 0.6 & $0 \cdot 7$ \\
\hline Methanol & $6.9(66.6)^{c}$ & $6.9(66.6)$ & $6.9(66 \cdot 4)$ & $6.9(66 \cdot 3)$ & $7 \cdot 0(66 \cdot 7)$ \\
\hline Acetic acid & $5 \cdot 0(25 \cdot 4)^{d}$ & $5 \cdot 0(25.4)$ & $5 \cdot 0(25 \cdot 4)$ & $5 \cdot 0(25 \cdot 2)$ & $5 \cdot 1(25 \cdot 5)$ \\
\hline Proteins & $4 \cdot 1$ & $4 \cdot 1$ & $4 \cdot 1$ & $4 \cdot 1$ & $4 \cdot 1$ \\
\hline
\end{tabular}

${ }^{a}$ Sugars are expressed in anhydroform $(\% \mathrm{w} / \mathrm{w})$.

${ }^{h}$ Measured by spectrophotometry.

Values in parentheses are degrees of methylation.

${ }^{\text {} V a l u e s ~ i n ~ p a r e n t h e s e s ~ a r e ~ d e g r e e s ~ o f ~ a c e t y l a t i o n . ~}$ 
injected material. The composition of the purified pectins is shown in Table 1 . The content of galacturonic acid was increased to $58.8 \%$ by the purification step. Arabinose, galactose and rhamnose were the main neutral sugars. Degrees of methylation and acetylation were 66.6 and $25.4 \%$, respectively. Even after purification, pectins contained small but significant amounts of proteins $(4 \cdot 1 \%)$ and phenolic compounds $(1 \cdot 1 \%)$. HPLC showed that ferulic acid was the major phenolic acid and the values obtained for the content of feruloyl groups $(0.7 \%)$ was similar to that obtained by spectrophotometry.

Chromatography on Sepharose CL-2B showed that pectins display fairly continuous variations of molecular weight and galacturonic acid to neutral sugars ratio suggesting that they are chemically heterogeneous. The intrinsic viscosity of the pectins was $247 \mathrm{ml} \mathrm{g}^{-1}$ and $M_{\mathrm{v}}$ was 45800 .

Characterisation of the pectins obtained after treatments with trifluoroacetic acid

The chemical composition of the pectins hydrolysed with $0 \cdot 1 \mathrm{M}$ trifluoroacetic acid at $25^{\circ} \mathrm{C}$ is shown in Table 1 . Minor changes were observed when compared to purified pectins. Galacturonic acid slightly increased to $59.6 \%$ while the neutral sugars slightly decreased to $23 \%$; the decrease in neutral sugars concerned only arabinose and xylose, the other sugars remaining constant. The feruloyl groups content $(0 \cdot 6-0 \cdot 7 \%)$, degree of methylation and degree of acetylation were not modified.

The hydrolysis kinetics of the pectins by $0.05 \mathrm{~m}$ trifluoroacetic acid at $100^{\circ} \mathrm{C}$ are shown in Fig. 1. Galacturonic acid was released up to an

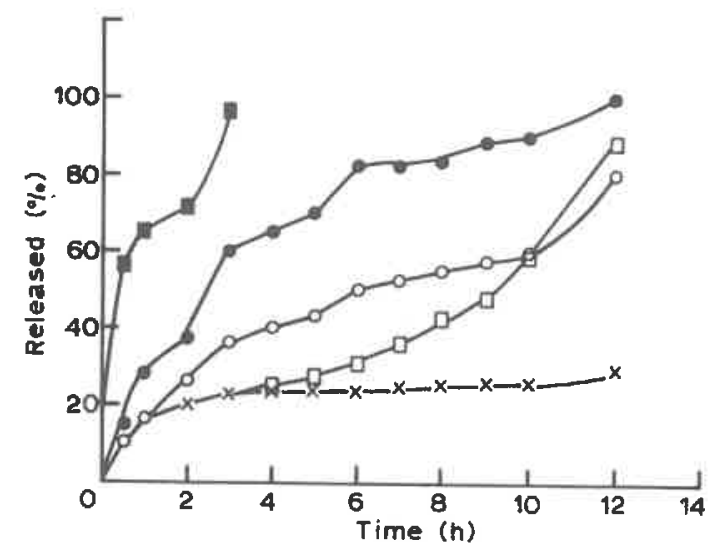

Fig. 1. Neutral sugars, galacturonic and ferulic acids released from beet pectins with $0.05 \mathrm{M}$ trifluoroacetic acid at $100^{\circ} \mathrm{C}$ as a function of time. Values (\%) are expressed relatively to the initial amount of the corresponding parent residues. (ㅁ) Rhamnose, (w) arabinose, $(0)$ galactose, $(\bullet)$ ferulic acid, $(\times)$ galacturonic acid. 
asymptotic limit of around $30 \%$. For the first $5 \mathrm{~h}$, the degree of hydrolysis of rhamnose was close to that of galacturonic acid but increased rapidly to $80 \%$ in $12 \mathrm{~h}$. Galactose was released in a similar manner. Arabinose was released more quickly as $-70 \%$ is released in $1 \mathrm{~h}$ and $100 \%$ after $3 \mathrm{~h}$. The release of feruloyl groups appeared to be a two step process. More than $50 \%$ of the feruloyl groups were released quickly together with $98 \%$ of the arabinose and $40 \%$ of galactose during the first $3 \mathrm{~h}$ while the remaining was liberated later with the residual galactose.

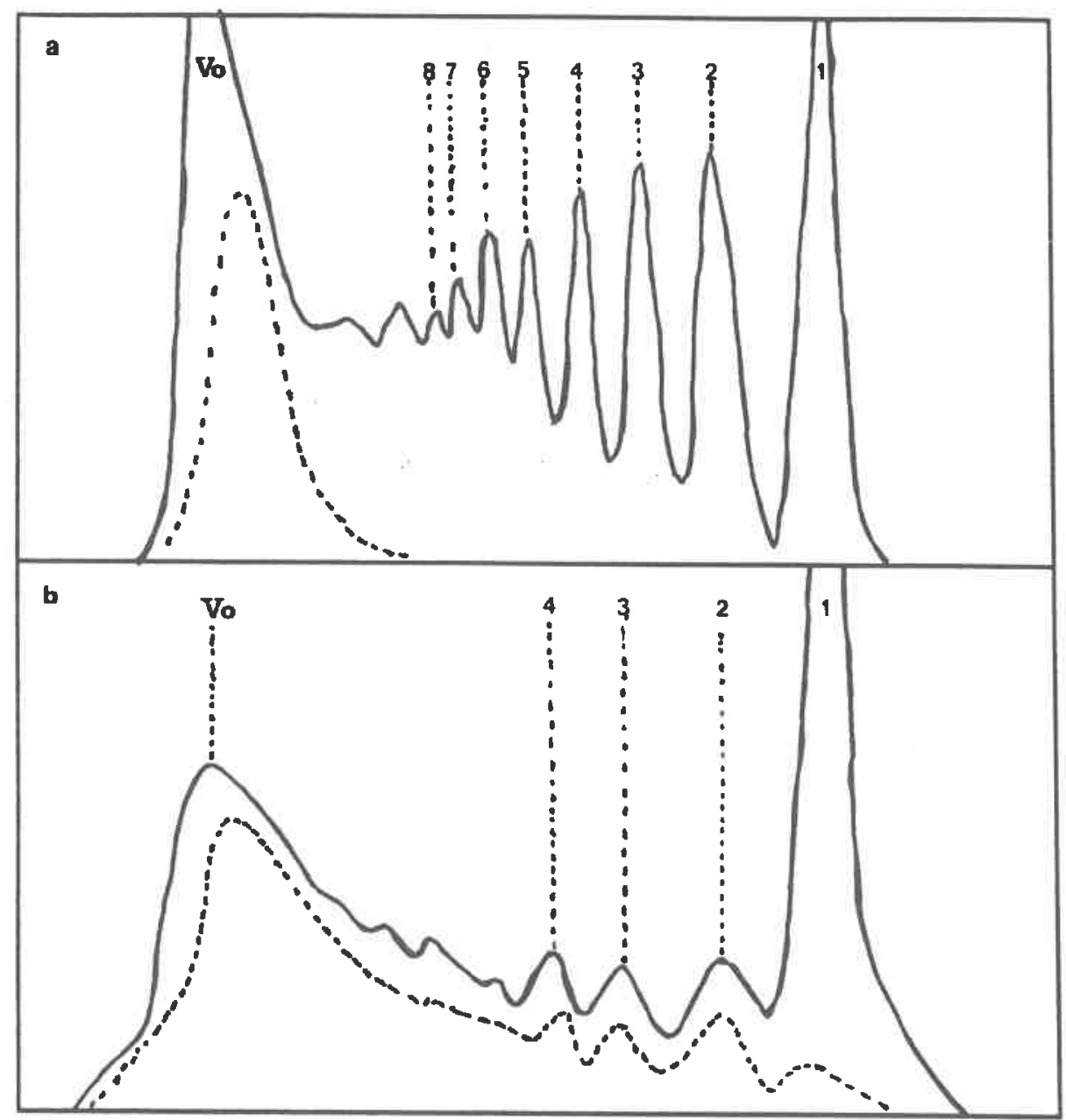

Fig. 2. Gel filtration chromatography on Bio-Gel P-2 of the products of beet pectins hydrolysis with $0.05 \mathrm{M}$ trifluoroacetic acid for: (a), $1 \mathrm{~h}$ and (b), $12 \mathrm{~h}$. (-- ) Absorption at $520 \mathrm{~nm}$ ( $m$-hydroxydiphenyl method); (-) absorption at $425 \mathrm{~nm}$ (orcinol method). $\mathrm{V}_{0}$, void volume. 
The dialysates of the hydrolysates were chromatographied on Bio-Gel P-2 (Fig. 2). The chromatogram of the dialysate of the hydrolysate $1 \mathrm{~h}$ showed material excluded from the column rich in galacturonic acid and rhamnose, and peaks eluted in the fractionation range of the column which contained arabinose as the major sugar with some traces of galactose and galacturonic acid (Table 2). No rhamnose was found in these peaks. Spectra of all these fractions showed a bathochromic shift of the double absorption peak at 300 and $325 \mathrm{~nm}$ (at pH 4.5) towards a single peak at $375 \mathrm{~nm}$ (at pH 10) which is indicative (Harborne, 1964) of the presence of ester-linked feruloyl groups. The chromatogram of the dialysate of the $12 \mathrm{~h}$-hydrolysate showed a main peak at an elution volume of $250 \mathrm{ml}$ (peak 1), a series of small peaks (2-6) and material excluded from the gel. Neutral sugars were mainly $(67.6 \%)$ recovered as monomers in peak 1 while galacturonic acid was present as oligomers in the peaks in the fractionation range of the column $(\sim 40.7 \%)$ and in the material at the void volume $(\sim 59 \cdot 3 \%)$ (Table 3 ). These results show that the neutral sugar side-chains and also the backbone can be hydrolysed by $0.05 \mathrm{M}$ trifluoroacetic acid.

The chemical composition of the retentates was indicated in Table 4. The galacturonic acid content increased to $77 \%$ and the neutral sugar content decreased to $5 \cdot 2 \%$ when the hydrolysis time was increased. The molar ratio arabinose to galactose had values between 0 (5-12 h) and

TABLE 2

Composition of the Fractions Obtained by Bio-Gel P-2 Chromatography After Hydrolysis of the Pectins with 0.05 M Trifluoroacetic Acid for $1 \mathrm{~h}$

\begin{tabular}{|c|c|c|c|c|c|c|c|c|c|}
\hline & \multicolumn{9}{|c|}{ Fractions } \\
\hline & $V_{0}$ & 8 & 7 & 6 & 5 & 4 & 3 & 2 & 1 \\
\hline & \multicolumn{9}{|c|}{ Recovery (\%) ${ }^{a}$} \\
\hline & $23 \cdot 9$ & $6 \cdot 2$ & $8 \cdot 7$ & $5 \cdot 1$ & $6 \cdot 3$ & $5 \cdot 1$ & 76 & $5 \cdot 2$ & $31 \cdot 9$ \\
\hline Galacturonic acid & $40 \cdot 3^{b}$ & $34 \cdot 3$ & $53 \cdot 7$ & $4 \cdot 2$ & $4 \cdot 3$ & $4 \cdot 1$ & $3 \cdot 9$ & $6 \cdot 6$ & $1 \cdot 3$ \\
\hline Rhamnose & $1 \cdot 8$ & - & - & - & - & - & - & - & - \\
\hline Arabinose & $44 \cdot 2$ & $53 \cdot 6$ & $37 \cdot 2$ & $93 \cdot 0$ & 91.9 & $85 \cdot 1$ & $92 \cdot 1$ & $87 \cdot 7$ & $90 \cdot 9$ \\
\hline Xylose & - & $3 \cdot 2$ & $3 \cdot 1$ & - & - & - & - & - & - \\
\hline Galactose & $11 \cdot 7$ & $8 \cdot 9$ & $6 \cdot 0$ & $3 \cdot 3$ & $3 \cdot 3$ & $5 \cdot 9$ & $3 \cdot 9$ & $5 \cdot 7$ & $7 \cdot 8$ \\
\hline Feruloyl groups $(\%)^{c}$ & $12 \cdot 9$ & - & $4 \cdot 0$ & $4 \cdot 8$ & $7 \cdot 4$ & $8 \cdot 3$ & $5 \cdot 2$ & $10 \cdot 1$ & $12 \cdot 3$ \\
\hline
\end{tabular}

${ }^{a}$ Expressed relative to the material injected on the Bio-Gel P-2 column.

${ }^{b}$ Expressed in relative weight percentages.

'Expressed relative to the feruloyl groups injected on the Bio-Gel P2 column. 
TABLE 3

Composition of the Fractions Obtained by Bio-Grel P-2 Chromatography After Hydrolysis of the Pectins with $0.05 \mathrm{M}$ Trifluoroacetic Acid for $12 \mathrm{~h}$

\begin{tabular}{|c|c|c|c|c|c|}
\hline & \multicolumn{5}{|c|}{ Fractions } \\
\hline & \multicolumn{4}{|c|}{ Recovery (\%) ${ }^{a}$} & 1 \\
\hline & $34 \cdot 5$ & $3 \cdot 7$ & $5 \cdot 9$ & $3 \cdot 9$ & $51 \cdot 9$ \\
\hline Galacturonic acid & $53 \cdot 0^{b}$ & $58 \cdot 0$ & $54 \cdot 3$ & $51 \cdot 4$ & $10 \cdot 0$ \\
\hline Neutral sugars $^{c}$ & $47 \cdot 0$ & $42 \cdot 0$ & $45 \cdot 7$ & $48 \cdot 6$ & $90 \cdot 0$ \\
\hline Feruloyl groups $(\%)^{d}$ & $17 \cdot 9$ & $1 \cdot 5$ & $22 \cdot 3$ & $30 \cdot 2$ & $25 \cdot 0$ \\
\hline
\end{tabular}

${ }^{a}$ Expressed relative to the material injected on the Bio-Gel P-2 column.

${ }^{b}$ Expressed in relative weight percentages.

'Neutral sugar' content was determined by colórimetry.

'Expressed relative to the feruloyl groups injected on the Bio-Gel-P2 column.

$0.98(1 \mathrm{~h})$. The content of feruloyl groups also decreased to $0 \cdot 1 \%$ in the $12 \mathrm{~h}$ hydrolysed sample. The degree of methylation slightly increased whereas the degree of acetylation was not changed. At least in the first hours $(5 \mathrm{~h})$ of hydrolysis, the protein material was not totally removed. The viscosity-average molecular weights decreased when the hydrolysis increased; the values for the samples treated for more than $5 \mathrm{~h}$ were not obtained because of the low amount of available material.

Characterisation of the pectins after enzymic treatments

Araf-ase released $\sim 18 \%$ of the arabinose after $24 \mathrm{~h}$ and this percentage increased to $\sim 28 \%$ after $48 \mathrm{~h}$. About $50 \%$ of the arabinose was removed by the sequential action of Araf-ase and endo-Ara-ase and was accompanied by $\sim 20 \%$ of the feruloyl groups and $\sim 4 \%$ of the galacturonic acid. The percentage of galactose released by Gal-ase was less than $26 \%$ whether the enzyme was used directly or after Araf-ase. It increased to $\sim 37 \%$ when Gal-ase and endo-Gal-ase were applied sequentially. About $16 \%$ of the feruloyl groups were released while only $2-3 \%$ of the galacturonic acid was liberated. All these enzymes used in combination removed $\sim 70 \%$ of the arabinose, $\sim 16 \%$ of the galactose and $\sim 38 \%$ of the feruloyl groups. Characteristics of the retentates are reported in Table 5. The galacturonic acid content increased up to $65 \%$ when enzymes were used in combination and the neutral sugar content decreased to $16 \%$. The molar ratio of arabinose to galactose had values 
Oxidative cross-linking of modified sugar-beet pectin

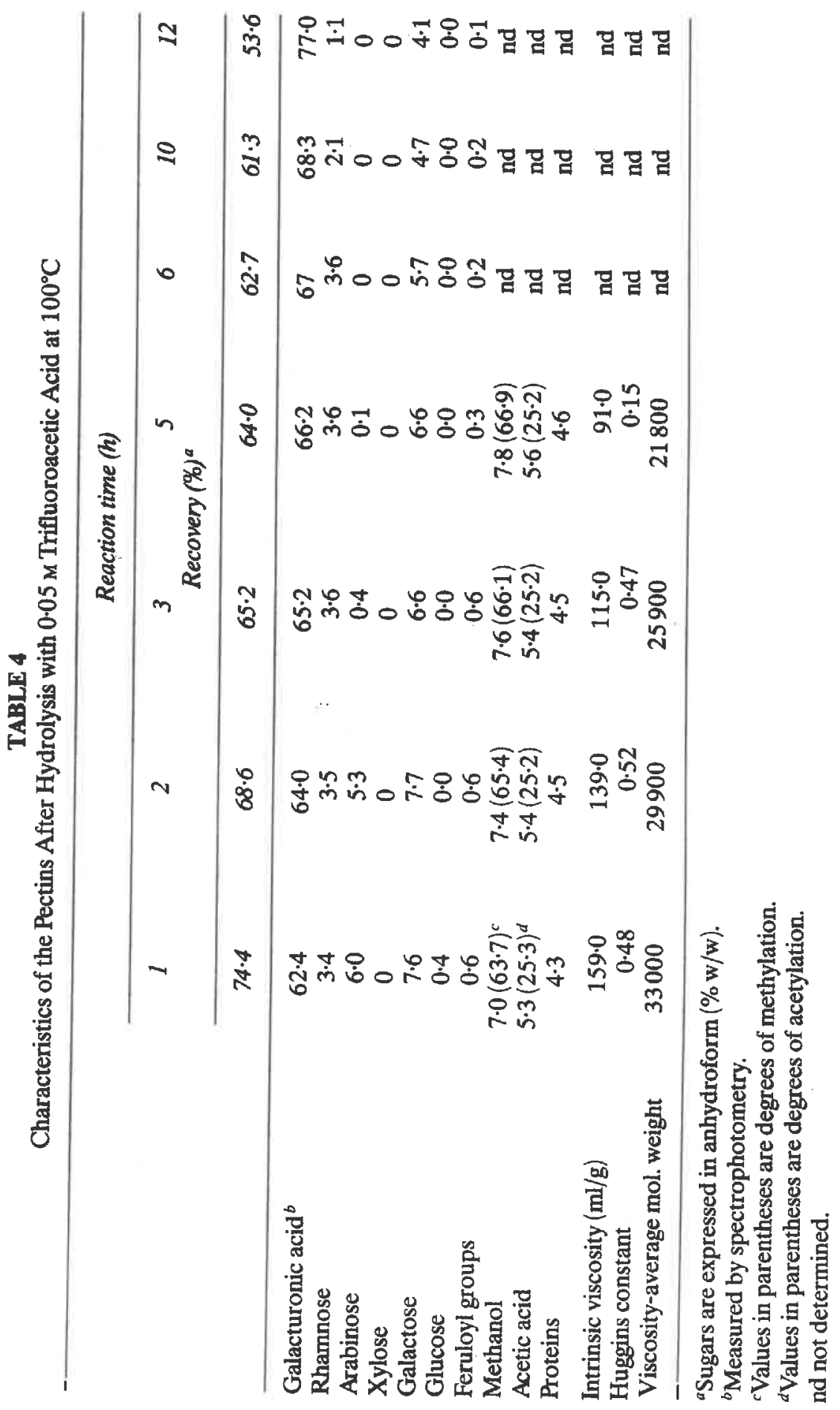




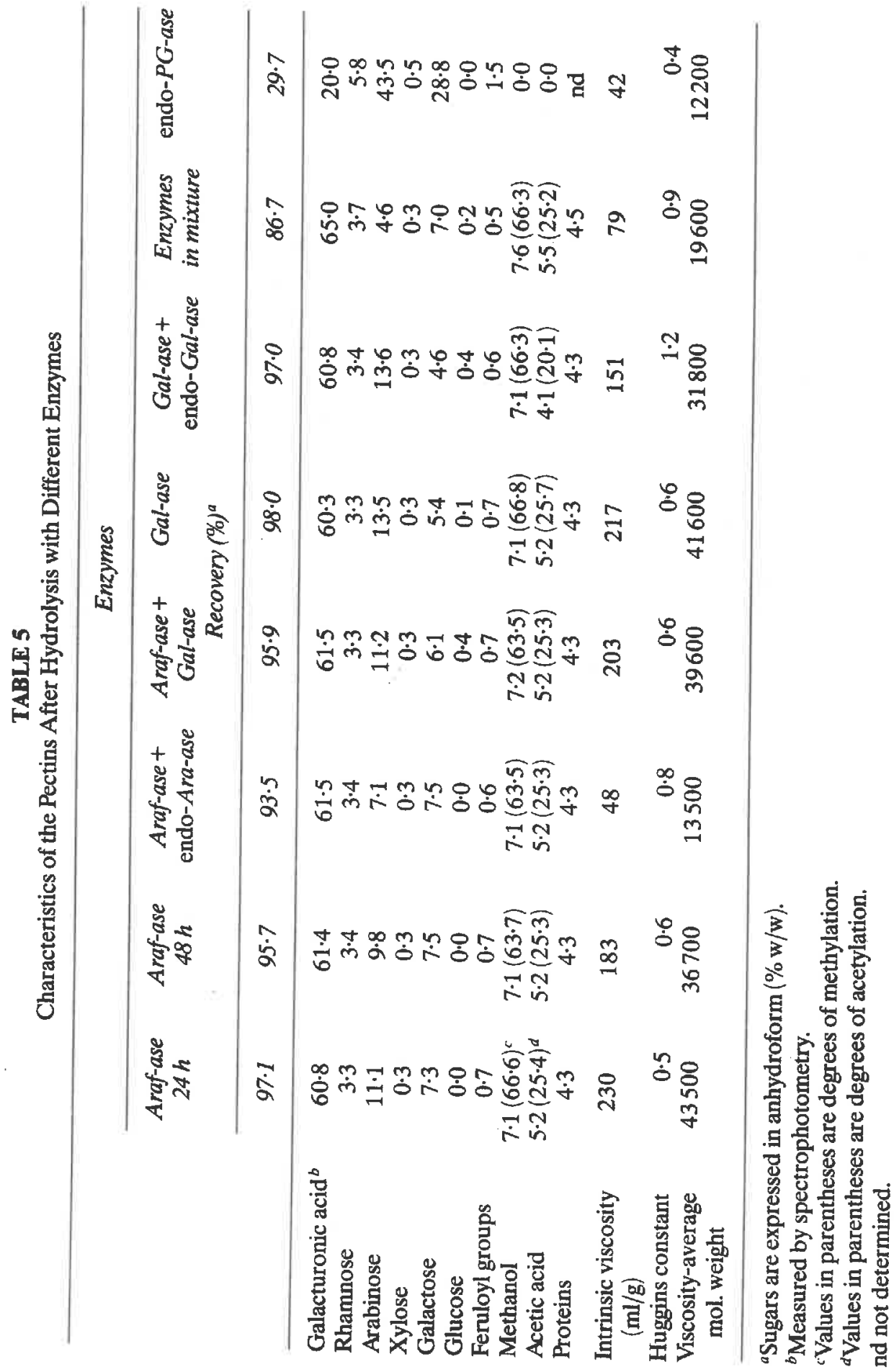


between 3.6 and $0 \cdot 8$. The feruloyl group content also decreased to $0.5 \%$. A decrease in the $M_{\mathrm{v}}$ was observed especially when endo-Ara-ase was applied. The percentage of hydrolysis by the endo-PG-ase of the pectins was $33 \%$, and the resistant material which accounted for $29.7 \%$ of the initial pectin, was rich in neutral sugars $(\sim 81 \%$ of the initial neutral sugars) and in feruloyl groups ( $\sim 81 \%$ of the initial feruloyl groups). The neutral sugar composition was close to that obtained for the initial pectins, arabinose being the major sugar followed by galactose and rhamnose. The $M_{v}$ of the 'hairy fragments' was 12200 (Table 5).

\section{Methylation analysis of some pectins}

Pectins initially and after cold $\left(25^{\circ} \mathrm{C}\right.$ for $\left.8 \mathrm{~h}\right)$ and hot $\left(100^{\circ} \mathrm{C}\right.$ for $\left.1 \mathrm{~h}\right)$ acidic treatments and after araf-ase hydrolysis (for $24 \mathrm{~h}$ ) were methylated. Only the derivatives from arabinose, galactose and rhamnose are reported since they account for $>90 \%$ of the neutral sugars (Table 6). Xylose and glucose occurred in amounts too low to be unambiguously characterised by their partially methylated derivatives. The sums of branch points and of terminal residues were equivalent showing that methylation was complete. The amounts of sugar calculated from the alditol acetate analysis and partially methylated alditol acetate analysis were in good agreement.

The distribution of the linkages was very similar in initial pectins and pectins after cold acid hydrolysis. Arabinofuranose, the major neutral sugar was mainly terminal, $(1 \rightarrow 3)$ - and $(1 \rightarrow 3,5)$-linked which was typical of a highly branched arabinan. Galactose was mainly terminal, $(1 \rightarrow 4)$-linked but some $(1 \rightarrow 3)-,(1 \rightarrow 3,4)$ - and $(1 \rightarrow 3,6)$-linkages were detected. This suggests the presence of both type of galactans, $(1 \rightarrow 4)$ linked galactans with few branching points on the C-3 and $(1 \rightarrow 3)$-, $(1 \rightarrow 6)$-linked (arabino)-galactans. The high proportion of terminal galactose may be explained by relatively short galactose side-chains. Rhamnose was $(1 \rightarrow 2)$-linked, part of which substituted mainly at position 4. When Araf-ase was applied for $24 \mathrm{~h}$, significant changes appeared in the distribution of the arabinose-linkages. Terminal and $(1 \rightarrow 3,5)$-linked arabinose residues decreased by $30 \%$ while the $(1 \rightarrow 5)$ linked increased by $\sim 50 \%$. A less branched arabinan was thus obtained, resulting from the preferential splitting by the enzyme of the $(1 \rightarrow 3)-\alpha-$ linkages. The concentrations of galactose and rhamnose in pectins were increased but no variation was noticed in the distribution of the galactosyl and rhamnosyl linkages. More extensive was the degradation of the side-chains with $0.05 \mathrm{M}$ acid for $1 \mathrm{~h}$ as $\sim 66 \%$ and $\sim 20 \%$ of the arabinose and galactose, respectively were removed. The relative pro- 


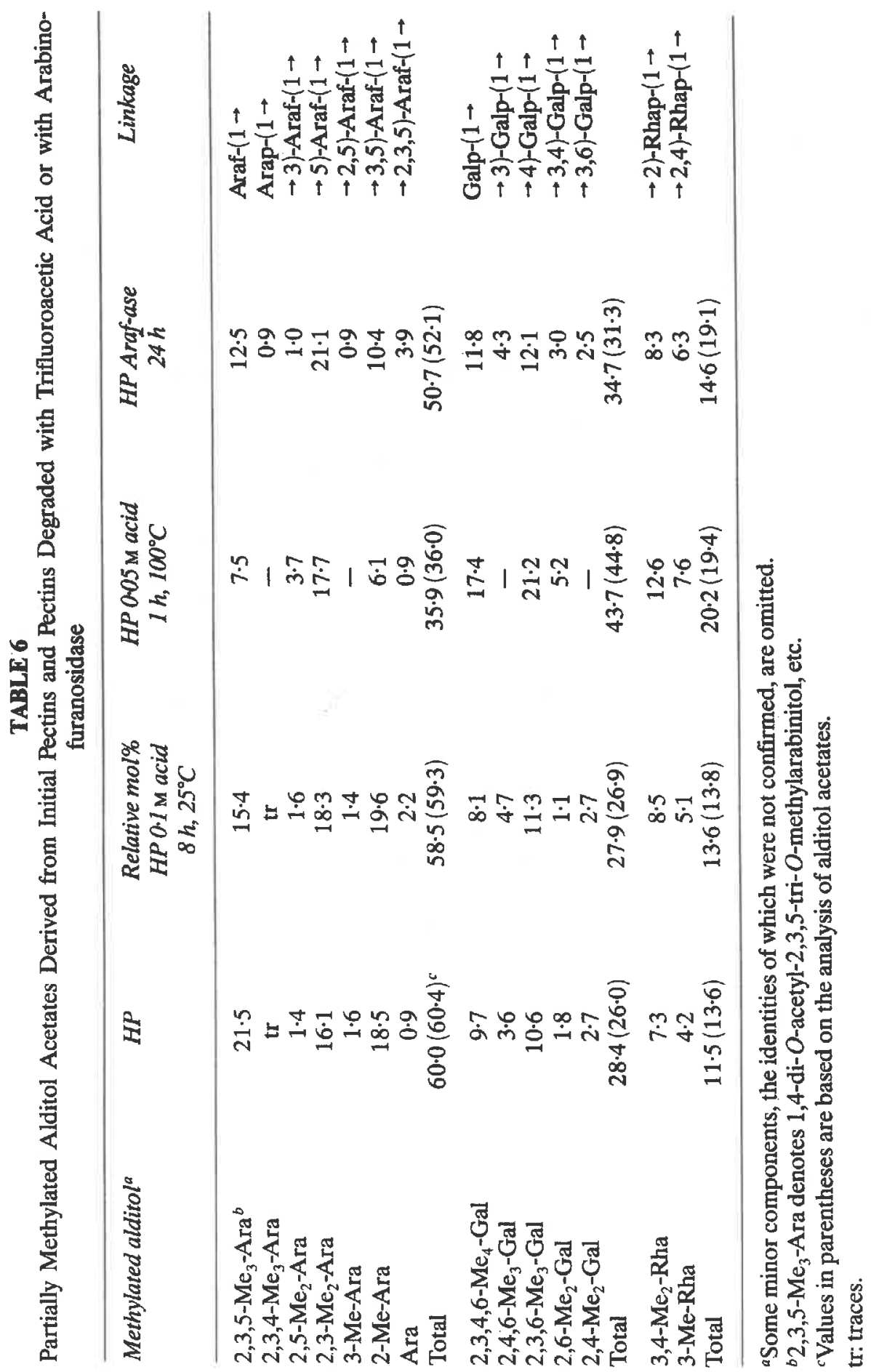


portions of $(1 \rightarrow 5)$-linked arabinose residues increased by $\sim 80 \%$, whereas the terminal and $(1 \rightarrow 3,5)$-linked residues decreased by $\sim 40 \%$, which indicated that the bonds involving non-reducing terminal units were cleaved faster than the inner ones. A slight decrease $(0 \cdot 9-0 \cdot 8)$ was observed in the relative proportion of terminal to $(1 \rightarrow 4)$-linked galactose residues between initial and degraded pectins and the branching points on the C-3 were not removed. In contrast, $(1 \rightarrow 3)$-, $(1 \rightarrow 6)$-linked galactose residues were not found in degraded pectins; this fact suggests that the main effect of the treatment with $0.05 \mathrm{M}$ acid at $100^{\circ} \mathrm{C}$ for $1 \mathrm{~h}$ was the debranching of the arabinans and the removal of type II (arabino)galactans from the side-chains. Rhamnose was mostly recovered and the proportion of $(1 \rightarrow 2)$ - to $(1 \rightarrow 2,4)$-linked was close to that reported with initial pectins showing that the number of branch points is not changed.

\section{Kinetics of the action of ammonium persulfate}

The action of the ammonium persulfate was followed spectrophotometrically. The pectins initially absorbed at $375 \mathrm{~nm}$ at $\mathrm{pH} 10$ due to the ester-linked feruloyl groups. When persulfate ions were added, the absorbance decreased to a limiting value which corresponds to the absorbance of the products of the reaction. Since the products were absorbed at the measured wavelength, it was not possible to directly relate the absorbances to the residual concentration in feruloyl groups. Equations (1) and (2) apply to first- and second-order reactions, respectively, where $\left(k_{\text {app }}\right)$ is the apparent rate constant

$$
\begin{aligned}
& \log \left[\left(A_{t}-A_{\infty}\right) /\left(A_{0}-{ }_{\infty}\right)\right]=-k_{\text {app }} t \\
& \left(A_{1}-A_{0}\right) /\left(A_{1}-A_{\infty}\right)=-k_{\text {app }}(\mathrm{F})_{0} t
\end{aligned}
$$

$A_{0}, A_{1}$ and $A_{\infty}$ are the absorbances at time $0, t$ and infinity, respectively, and $(F)_{0}$ is the initial concentration of the feruloyl groups. For some samples, the reaction was very slow and the limiting absorbance was considered to account for $20 \%$ of the initial value according to previous results (Thibault et al., 1987). The rate constant $\left(k_{2}\right)$ was obtained by:

$$
k_{2}=k_{\text {app }} /[\text { ammonium persulfate }]_{0}
$$

A straight line was always obtained with eqn (1) but not with eqn (2) which indicated that the kinetics of the disappearance of feruloyl groups followed a pseudo-first order law with respect to pectin concentration for all the samples (Fig. 3). The absorbance at infinity can also be determined by the method of Kezdy and Swinbourne (Espenson, 1981) which 


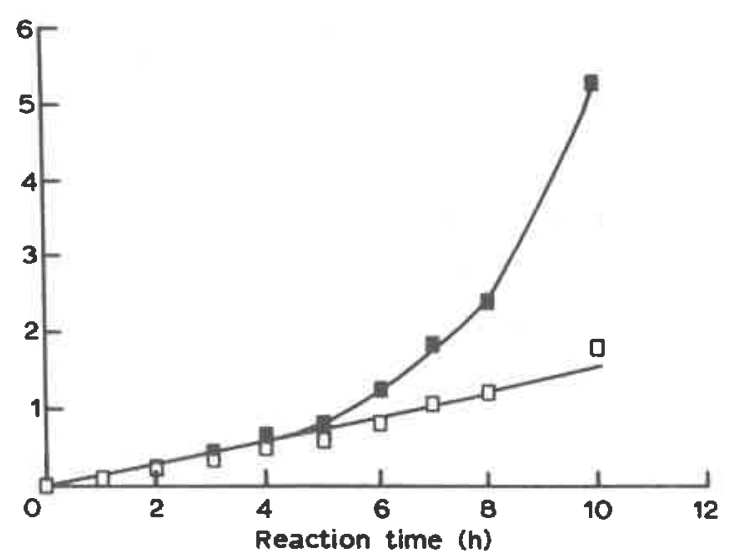

Fig. 3. Kinetics of the action of ammonium persulfate on purified beet pectins $(0 \cdot 44 \%$ in $0.04 \mathrm{M}$ ammonium persulfate at $\left.37^{\circ} \mathrm{C}\right)$; (ㅁ) $\log \left(A_{t}-A_{\infty}\right) /\left(A_{0}-A_{\infty}\right)$ analysed in terms of pseudo-first order and, $(\omega)\left(A_{f}-A_{0}\right) /\left(A_{\infty}-A_{r}\right)$ analysed in terms of pseudo-second order with respect to feruloyl groups.

gives a direct value of $k_{\mathrm{app}}$ and which leads to the calculation of $k_{2}$ without the introduction of $A_{\infty}$ :

Consider the pseudo-first-order kinetic data at time $t$ and at a later time $\tau$, the value of the absorbance $(A)$ at each time is

$$
\begin{aligned}
& A_{t}=\left(A_{0}-A_{\infty}\right) \exp \left(-k_{\text {app }} t\right)+A_{\infty} \\
& A_{t+\tau}=\left(A_{0}-A_{\text {o }}\right) \exp \left[-k_{\text {app }}(t+\tau)\right]+A_{\infty}
\end{aligned}
$$

Dividing the first equation by the second we have

$$
\left(A_{t}-A_{\infty}\right) /\left(A_{t+\tau}-A_{\infty}\right)=\exp \left(k_{\text {app }} \tau\right)
$$

and solving for $A_{\imath}$, gives

$$
A_{t}=A_{\infty}\left[\exp \left(k_{\text {app }} \tau\right)-1\right]+A_{t+\tau} \exp \left(k_{\text {app }} \tau\right)
$$

The first term on the right is time independent. Hence a plot $A_{t}$ versus $A_{t+\tau}$ would be linear with a slope of $\exp \left(k_{\mathrm{app}} \tau\right)$. Since at the end point, $A_{t}=A_{t+\tau}$, the intersection of the line through the data points with the $45^{\circ}$ line gives the value of $A_{\infty}$. The values obtained corresponded to $\sim 20 \%$ of the initial absorbance of the feruloyl groups (Guillon, 1987) and were in agreement to the experimental ones. The $k_{2}$ values were low for all the samples (range $0.2310^{-3}-1.0610^{-3} \mathrm{M}^{-1} \mathrm{~s}^{-1}$ ) (Table 6). Values for the initial pectins and their 'hairy fragments' were close which confirms that only the part of the rhamnogalacturonic backbone which carries the feruloylated neutral sugars was involved in the cross-linking. The highest 
values were obtained for pectins degraded by hot $0.05 \mathrm{M}$ acid with a maximum after $6 \mathrm{~h}\left(1.0710^{-3} \mathrm{M}^{-1} \mathrm{~s}^{-1}\right)$. Amongst the enzyme treated pectins, the highest values were obtained after hydrolysis with enzyme in combination $\left(0.8710^{-3} \mathrm{M}^{-1} \mathrm{~s}^{-1}\right)$. A slight increase in the $k_{2}$ values was observed after cold acid hydrolysis for $24 \mathrm{~h}$ and $72 \mathrm{~h}$ and after sequential hydrolysis with Araf-ase and Gal-ase.

TABLE 7

Values of the Rate Constant (k) of the Reaction of Ammonium Persulfate on Beet Pectins and Results of the Gelification Tests

\begin{tabular}{lcc}
\hline \multicolumn{1}{c}{ Pectins $\left(\mathrm{H}^{+}\right.$form $)$} & $k \times 10^{3}\left(\mathrm{M}^{-1} \times s^{-1}\right)$ & Gelification test \\
\hline Initially & 0.23 & - \\
After $0.1 \mathrm{M}$ TFA hydrolysis at $25^{\circ} \mathrm{C}$ for $8 \mathrm{~h}$ & 0.26 & $+(\geqslant 5$ days $)$ \\
After 0.1 M TFA hydrolysis at $25^{\circ} \mathrm{C}$ for $24 \mathrm{~h}$ & 0.40 & $+(\geqslant 5$ days $)$ \\
After $0.1 \mathrm{M}$ TFA hydrolysis at $25^{\circ} \mathrm{C}$ for $72 \mathrm{~h}$ & 0.60 & - \\
After 0.05 M TFA hydrolysis at $100^{\circ} \mathrm{C}$ for $1 \mathrm{~h}$ & 0.27 & - \\
After $0.05 \mathrm{M}$ TFA hydrolysis at $100^{\circ} \mathrm{C}$ for $2 \mathrm{~h}$ & 0.36 & - \\
After 0.05 M TFA hydrolysis at $100^{\circ} \mathrm{C}$ for $3 \mathrm{~h}$ & 0.64 & - \\
After 0.05 M TFA hydrolysis at $100^{\circ} \mathrm{C}$ for $5 \mathrm{~h}$ & 0.73 & - \\
After $0.05 \mathrm{M}$ TFA hydrolysis at $100^{\circ} \mathrm{C}$ for $6 \mathrm{~h}$ & $1 \cdot 07$ & - \\
After 0.05 M TFA hydrolysis at $100^{\circ} \mathrm{C}$ for $10 \mathrm{~h}$ & 0.72 & $+(48 \mathrm{~h})$ \\
After $0.05 \mathrm{M}$ TFA hydrolysis at $100^{\circ} \mathrm{C}$ for $12 \mathrm{~h}$ & 0.68 & - \\
After Araf-ase hydrolysis for $24 \mathrm{~h}$ & 0.23 & - \\
After Araf-ase hydrolysis for $48 \mathrm{~h}$ & 0.24 & $+(72 \mathrm{~h})$ \\
After Araf-ase and endo-Ara-ase hydrolysis & 0.24 & - \\
After Araf-ase and Gal-ase hydrolysis & 0.46 & - \\
After Gal-ase hydrolysis & 0.33 & - \\
After Gal-ase and endo-Gal-ase hydrolysis & 0.23 & - \\
After hydrolysis with enzymes in combination & 0.87 & - \\
'Hairy' fragments & 0.30 & \\
\hline
\end{tabular}

a'TFA: trifluoroacetic acid.

Values in parentheses correspond to the setting time of the gelling pectins.

\section{Gelling of the pectic samples}

When solutions were made with a $1.5 \%$ pectin concentration and $0.01 \mathrm{M}$ ammonium persulfate and left at $25^{\circ} \mathrm{C}$, only a few gelled and amongst the gelling pectins, the setting times were different (Table 7). Pectins degraded by Araf-ase for $24 \mathrm{~h}$ gelled after a reaction time of $48 \mathrm{~h}$ while pectins after sequential hydrolysis with Araf-ase and Gal-ase gelled after $72 \mathrm{~h}$. Pectins treated with cold acid for $8 \mathrm{~h}$ and $24 \mathrm{~h}$ gelled after 5 days. 


\section{DISCUSSION}

\section{Comparison of the pectins obtained by acid and enzymic treatments}

The extraction of the pectins from sugar-beet pulp was performed in the same way as previously described (Rombouts \& Thibault, 1986a) and the amounts of pectins solubilised by hot dilute acid were similar. Because of the large amount of material needed for this study, purification with copper acetate was preferred rather than purification by ion exchange chromatography. Purified pectins have fairly low molecular weights and are relatively rich in neutral sugars with arabinose, galactose and rhamnose as major neutral sugars, this being in agreement with previous work (Rombouts \& Thibault, 1986a; Guillon \& Thibault, 1988). However, they have higher galactose contents.

Pectins obtained after cold dilute acid treatments had a similar chemical composition to the initial pectins, although a slight decrease in arabinose was observed. In contrast, pectins obtained after hydrolysis with hot dilute acid have different chemical compositions varying with the hydrolysis time. In the first hydrolysis period, arabinose residues, especially peripheral ones, were mostly removed together with part of the feruloyl groups and the resulting pectins were rich in galactose, rhamnose and galacturonic acid. With increasing hydrolysis time, pectins became free of arabinose and decreasing amounts of galactose and feruloyl groups were recovered. During the last stage, the decrease in rhamnose content suggests the breakdown of the pectic backbone. This was confirmed by the decrease in the intrinsic viscosity and by the elution pattern of the products on the Bio-Gel P-2 column. The fact that the release of feruloyl groups was concomitant to that of neutral sugars confirmed that they were linked either to arabinosyl or galactosyl units in the side-chains. These results were in agreement with previous work (Guillon \& Thibault, 1989; Guillon et al., 1989).

The composition of the pectin products following enzymic degradation depended on the enzymes used. Araf-ase preferentially removed peripheral arabinosyl units leading to less branched arabinans. The increase in the incubation time period was not accompanied by a substantial increase in the arabinose release, and the value for $48 \mathrm{~h}$ was lower than that previously obtained (Guillon et al., 1989) for the 'hairy fragments' from demethylated and deacetylated pectins. Possibly, some arabinosyl residues in pectins may carry acetyl substituents which limit hydrolysis. Gal-ase which was active preferentially towards short $\beta$ $(1 \rightarrow 4)$-linked galactans, removed only some galactosyl units. However, the hydrolysis was more extented than previously reported (Guillon et 
al., 1989) for 'hairy fragments' from sugar-beet pectins; this was consistant with the fact that the pectins studied here are richer in galactose and especially in $(1 \rightarrow 4)$-links than those previously studied. The action of the enzyme was not enhanced by a previous action of Araf-ase which rules out the occurrence in sugar-beet pectins of $(1 \rightarrow 4)$ linked galactans carrying on $\mathrm{C}-3$, short side-chains of $(1 \rightarrow 5)$-linked arabinosyl units as described in potato (Jarvis et al., 1981 $a, b$ ) or in lupine (Carré et al., 1985). The limited degradation of side-chains by Araf-ase could result from the presence of some galactosyl, arabinopyranosyl and feruloyl residues attached to the main core (Guillon, 1987). Similarly, Gal-ase action might be limited by the presence of some feruloyl groups and of some branching points on the main core. The hydrolysis with successive Araf-ase and endo-Ara-ase removed about half of the arabinosyl units while Araf-ase-endo-Ara-ase used in mixture released up to $70 \%$ of the arabinosyl units. This synergestic effect of the enzymes was previously reported by Guillon et al., (1989); the endo-Ara-ase splits off linearised sequences and releases oligoarabinosides, some of which carry ester-linked feruloyl groups, galactosyl or arabinopyranosyl units. Thus, a further action of Araf-ase was possible on the arabinose side-chains free of feruloyl groups, galactosyl and arabinopyranosyl. In contrast a sequential action of Gal-ase and endo-Gal-ase did not markedly increase the amount of galactose removed; this may be explained by the presence of branching points on the $\mathrm{C}-3$ of some galactosyl units and the relatively low degree of polymerisation as suggested by methylation analysis.

\section{Gelling ability of pectins}

The initial pectins did not and not all the modified pectins are able to gel. Only pectins after cold acid hydrolysis for 8 and $24 \mathrm{~h}$ and after hydrolysis with exo-enzymes, gel. Amongst the gelling pectins, there are differences in the setting times of the gels but the rate constants for the disappearance of feruloyl groups remained close to that obtained for the initial pectins. The rate constant for the disappearance of feruloyl groups is therefore not a good criterion for determining the gelation ability of pectins. This was previously observed by Thibault (1988) and was ascribed to the fact that the $k_{2}$ value reflects the rate of disappearance of feruloyl groups but not the rate of cross-linking; other reactions such as oxidations of the feruloyl residues, may lead to a decrease in the amount of feruloyl groups. The content in feruloyl groups is not an appropriate parameter since initial pectins, pectins after cold acid (for 8 and $24 \mathrm{~h}$ ) or after exo-enzyme hydrolysis have similar contents of feruloyl groups but different gelling capacities. Neither are the degrees of methylation and 
acetylation or the total amount in neutral sugars an appropriate index of gelation behaviour. These results confirm that no simple relationships exist between the gelling ability and chemical characteristics of pectins. The explanation of the different behaviors of pectins in the presence of ammonium persulfate must be in the fine structure and location of the feruloyl groups on the side-chains. In spite of the fact that the feruloyl groups are mostly $(\sim 60-70 \%$ ) carried by the galactosyl units (Guillon et al., 1989), the galactose side-chains are not involved in gelation. This conclusion arises from the fact that the selective removal of unsubstituted galactosyl units with or without the concomittant action Araf-ase and endo-Ara-ase does not improve the gelling ability of the pectins, although these enzymes should expose feruloyl groups carried by galactose residues. In contrast, pectins obtained from cold acid hydrolysis, which have the same general structural features as the initial material and differ only by a slight decrease in the arabinosyl content, are able to gel. This result is in agreement with those from Araf-ase ( $24 \mathrm{~h}$ ) hydrolysis. The feruloyl groups $(\sim 30 \%)$ carried by the arabinose side-chains are located some way away from the rhamnogalacturonic backbone, close to the non-reducing end, but are not directly accessible for the cross-linking reaction. Their accessibility was improved by a selective removal of peripheral arabinose free of feruloyl groups and thus, the gelling ability of pectins was increased. The fact that the pectins after hydrolysis with Araf-ase for $48 \mathrm{~h}$ are not able to gel could be explained by a degradation of the pectic backbone as suggested by the decrease in the intrinsic viscosity due to the hydrolysis $\left(\mathrm{pH} 5,30^{\circ} \mathrm{C}\right)$ which could promote some $\beta$-eleminative degradation.

In conclusion, feruloyl groups carried by the arabinose side-chains were those mainly involved in the gelation process and attention has to be paid to the conditions of extraction of beet pectins; too drastic treatment involving hot acid which would induce the breakdown of the very labile arabinosyl linkages and the release of some feruloyl groups would have to be excluded if gelling pectins are to be produced.

\section{ACKNOWLEDGEMENTS}

The authors wish to thank Mrs M. J. Crépeau (from their Institute) for excellent technical assistance and Pr F. M. Rombouts, Dr A. G. J. Voragen and Pr W. Pilnik (Department of Food Science, Agricultural University of Wageningen, The Netherlands) for the gift of arabinan- and galactan-degrading enzymes. 


\section{REFERENCES}

Beldman, G., Voragen, A. G. J., Rombouts, F. M. \& Pilnik, W. (1982). Enzymic liquefaction and saccharification of agricultural biomass. In Energy from Biomass: 2nd EC Conference, ed. A. Strub, P. Chartier \& G. Schleserer. Applied Science Publishers, London, pp. 1064-9.

Bertin, C., Rouau, X. \& Thibault, J. F. (1988). Structure and properties of sugar beet fibres. J. Sci. Food. Agric., 44, 15-29.

Blakeney, A. B., Harris, P. J., Henry, R. J. \& Stone, B. A. (1983). A simple and rapid preparation of alditol acetates for monosaccharides analysis. Carbohydr. Res., 113, 291-9.

Carre, B., Brillouet, J. M. \& Thibault, J. F. (1985). Characterization of polysaccharides from white lupin (Lupinus albus L.). J. Agric. Food Chem., 33, 285-92.

Crepeau, M. J. \& Thibault, J. F. (1988). Dosage des acides phénoliques dans les pectines de pulpes de betterave. Cahiers des Techniques de I'INRA, 18, 33-42.

Espenson, N. J. H. (1981). Reaction with a simple kinetic form. In Chemical Kinetics and Reaction Mechanisms. McGraw Hill, New York, pp. 12-41.

Fry, S. C. (1982). Phenolic components of the primary cell wall. Feruloylated disaccharides of $\mathrm{D}$-galactose and L-arabinose from spinach polysaccharides. Biochem. J., 203, 493-504.

Fry, S. C. (1983). Feruloylated pectic substances from the primary cell wall: their structure and possible functions. Planta, 157, 111-23.

Guillon, F. (1987). Etude de la structure chimique des chaines latérales des pectines de pulpes de betterave par des méthodes chimiques et enzymatiques. Contribution à l'étude de la réticulation par le persulfate d'ammonium. PhD thesis, University of Nantes, France.

Guillon, F. \& Thibault, J. F. (1988). Further characterisation of acid and alkalisoluble pectins from sugar beet pulp. Lebensm Wiss Technol., 21, 198-205.

Guillon, F. \& Thibault, J. F. (1989). Methylation analysis and mild acid hydrolysis of the 'hairy' fragments of sugar-beet pectins. Carbohydr. Res., 190, 85-96.

Guillon, F., Thibault, J. F., Rombouts, F. M., Voragen, A. G. J. \& Pilnik, W. (1989). Enzymic hydrolysis of the 'hairy' fragments of sugar beet-pectins. Carbohydr. Res., 190, 97-108.

Harborne, J. B. (1964). Phenolic compounds. In Methods in Polyphenol Chemistry, ed. J. B. Pridham. Pergamon, Oxford, pp. 33-41.

Jarvis, M. C., Threlfall, D. R. \& Friend, J. (1981a). The polysaccharide structure of potato cell walls: chemical fractionation. Planta, 152, 93-100.

Jarvis, M. C., Threlfall, D. R. \& Friend, J. (1981b). Potato cell wall polysaccharides degradation with enzymes from Phytophtora infestans. J. Exp. Bot., 32, 1309-19.

McCready, R. M. (1966). Polysaccharides of sugar beet pulp, a review of their chemistry. J. Am. Sugar Beet Technol., 14, 260-70.

Michel, F., Thibault, J. F., Barry J. L., de Baynast, R. (1988). Preparation and characterisation of dietary fibre from sugar beet pulp. J. Sci. Food Agric., 42, 77-85.

Michel, F., Thibault, J. F., Mercier, C., Heitz, C. \& Pouillaude, F. (1985). Extrac- 
tion and characterization of pectins from sugar beet pulp. Food Sci., 501, 1499-502.

Nelson, N. (1944). A photometric adaptation of the somogyi method for the determination of glucose. J. Biol. Chem., 153, 378 .

Owens, H. S., Lotzkar, H., Schultz, T. H. \& Maclay, W. D. (1946). Shape and size of pectinic acid molecules from viscometric measurement. J. Am. Chem. Soc., 68, 1628-32.

Phatak, L., Chang, K. C. \& Brown, G. (1988). Isolation and characterization of pectin in sugar-beet pulp, J. Food Sci., 53, 830-3.

Pippen, E. L., McCready, R. M. \& Owens, H. S. (1950). Gelation properties of partially acetylated pectins. J. Am. Chem. Soc., 72, 813-16.

Potty, V. H. (1969). Determination of proteins in presence of phenol and pectins. Anal. Biochem., 29, 535-8.

Rombouts, F. M. \& Thibault, J. F. (1986a). Feruloylated pectic substances from sugar-beet pulp. Carbohydr. Res., 154, 177-88.

Rombouts, F. M. \& Thibault, J. F. (1986 b). Enzymatic and chemical degradation and the fine structure of pectins from sugar-beet pulp. Carbohydr. Res., 154, 189-203.

Rombouts, F. M., Thibault, J. F. \& Mercier, C. (1983). Procédé de modification des pectines de betterave, produits obtenus et leurs applications. French Patent 8307 208.(1985). Chem. Abstr., 102,(1985) 60792u.

Rombouts, F. M., Voragen, A. G. J., Searle-van Leeuwen, M. J. F., Gereads, C. C. J. M., Schols, H. A. \& Pilnik, W. (1988). The arabinanases of Aspergillus niger. purification and characterisation of two $\alpha$-L-arabinofuranosidases and endo-1, 5- $\alpha$-L-arabinanase. Carbohydr. Polymers, 9, 25-47.

Thibault, J. F. \& Mercier, C. (1977). Aspergillus niger endopolygalacturonase. I-Studies on the purification by agarose gel chromatography. J. Solid-phase Biochem., 2, 295-304.

Thibault, J. F. (1979). Automatisation du dosage des substances pectiques par la méthode au méta-hydroxydiphényl. Lebensm. Wiss Technol., 12, 247-51.

Thibault, J. F. (1986). Some physical properties of sugar beet pectins modified by oxidative cross linking. Carbohydr. Res., 155, 183-92.

Thibault, J. F. (1988). Characterization and oxidative crosslinking of sugar-beet pectins extracted from cossettes and pulps under different conditions. Carbohydr. Polymers, 8, 209-23.

Thibault, J. F. \& Rombouts, F. M. (1986). Effects of some oxidizing agents, especially ammonium persulfate on sugar-beet pectins. Carbohydr. Res., 154,

Thibault, J. F., Garreau, C. \& Durand, D. (1987). Kinetics and mechanism of the reaction of ammonium persulfate with ferulic acid and sugar-beet pectins. Carbohydr. Res., 163, 15-27.

Tollier, M. T. \& Robin, J. P. (1979). Adaptation de la méthode à l'orcinol sulfurique au dosage automatique des glucides neutres totaux. Ann Technol Agric., 28, 1-15.

Voragen, A. G. J., Schols, H. A. \& Pilnik, W. (1986). Determination of the degree of methylation and acetylation of pectins by h.p.l.c. Food hydrocolloids, 1, 65-70.

Voragen, A. G. J., Rombouts, F. M., Searle-van Leeuwen, M. J. F., Schols, H. A. \& Pilnik, W. (1987). The degradation of arabinans by endo-arabinanase and arabinofuranosidases purified from Aspergillus niger. Food hydrocolloids, 